\title{
Dairy farmers' perspectives on antibiotic use: A qualitative study
}

\author{
Klara Fischer, ${ }^{1 *}$ Karin Sjöström, ${ }^{2}$ Arvid Stiernström, ${ }^{1}$ and UIf Emanuelson ${ }^{2}$ \\ ${ }^{1}$ Department of Urban and Rural Development, PO Box 7012, SE-750 07 Uppsala, Sweden \\ ${ }^{2}$ Department of Clinical Sciences, PO Box 7054, SE-750 07 Uppsala, Sweden
}

\section{ABSTRACT}

An important step in limiting the development of antibiotic resistance is reducing use of antibiotics in animal husbandry. Much research in this area has focused on individual farmer behavior, aiming to better align actual use with medical recommendations. However, farmers' practices and reasoning around their antibiotic use do not reflect solely that farmer as an individual. Rather, practices and worldviews are guided by context (e.g., veterinary advice, peer pressure, regulation, and interactions with farm animals). Studies that jointly embrace farmer agency and the wider structures for this agency, however, remain scarce. This paper draws on theories of behavior as socially constructed, and in particular on the concept of the "good farmer," to interpret findings from a study of 7 Swedish dairy farms. The results show that all farmers have close daily contact with their animals, have strong emotional ties, and place emphasis on the importance of being able to judge animal health status by eye. Half of the farms use an automatic milking system, and for these farmers automation means better monitoring of animal health without losing contact with the cows. The local veterinarian is considered a positive and important authority whose advice is valued. Despite comparatively strict antibiotic use regulations in Sweden, the farmers do not report lack of access to antibiotics when needed. However, they report feeling disadvantaged in international trade and poorly treated by the Swedish government, which allows imports of cheaper meat and dairy products produced under less strict regulations. The farmers are well informed about how to prevent and treat common diseases. In cases where they do not follow recommendations, we found that economic and labor constraints are the reason rather than lack of knowledge. We concluded that structural limitations faced by farmers, rather than lack of information, impose constraints to further limiting antibiotic use in Sweden. Overall stricter and more uniform global regulations on

Received May 4, 2018.

Accepted October 13, 2018.

*Corresponding author: klara.fischer@slu.se antibiotic use in animal farming could be an effective measure for reducing antibiotic use.

Key words: dairy, farmer behavior, antibiotic, biosecurity

\section{INTRODUCTION}

Antibiotics are critical in human and veterinary medicine for treatment of severe infectious diseases. They also remain difficult to replace with equally effective alternatives. Thus, antibiotic resistance is one of the greatest threats to global human and animal health today. Although resistance development is complex and not completely understood, an acknowledged important step in limiting the development of antibiotic resistance is to limit use and ensure correct usage when antibiotics are needed (WHO, 2017). A significant share of antibiotic use today is in animal husbandry, and two-thirds of the predicted growth in antibiotic use globally is in this sector. Thus, it is widely acknowledged that research and policy efforts toward reducing use of antibiotics in animal husbandry are needed (FAO, 2016).

Much research has recently been directed at farmer behavior with regard to antibiotic use, with the purpose of better aligning actual use with medical recommendations (e.g., Buller et al., 2015; Jones et al., 2015; FAO, 2016; Lam et al., 2017). Our standpoint in this paper is that we need to understand not only farmers' behavior per se (i.e., their agency) but also the underlying reasons and the wider situation in which these behaviors occur (the structures). Farmers' use of antibiotics does not occur in isolation but rather is an outcome of the dialectic agency-structure relationship that characterizes society. As such, it is a result of farmers' own ideas and practices, veterinary advice, peer pressure, regulations, interactions with farm animals, and so on (Burton et al., 2012; Hamilton, 2017). The relative importance of various factors has to be empirically studied; however, in studies of antibiotic use in dairy farming, there has so far been an overall bias to the agency side of the agency-structure dynamic. The need for studying farm practices in their wider context is acknowledged in a few recent studies on antibiotics (Buller et al., 2015; Swinkels et al., 2015) and on adop- 
tion of biosecurity measures more generally (Higgins et al., 2018; Shortall et al., 2018), but the topic remains understudied (Swinkels et al., 2015).

In this paper, we seek to improve understanding of the wider situation shaping farmers' practices in relation to antibiotics in dairy farming. We address the topic through an in-depth study of Swedish dairy farmers' general farm practices, relations with veterinary services, antibiotic use, and perceived challenges.

To date, there have been few social science studies on antibiotic use and resistance in farming. An extensive systematic review by Buller et al. (2015) identified 114 peer-reviewed articles that address factors influencing antibiotic use in livestock farming. Although many of these assess farmers' and veterinarians' beliefs and practices, only 3 papers (McIntosh et al., 2009; Jan et al., 2010; Swinkels et al., 2015) include at least 1 social scientist in the list of authors. Two of these 3 studies (McIntosh et al., 2009; Jan et al., 2010) rely on the same data set and study veterinarians rather than farmers. The third study (Swinkels et al., 2015) focuses on farmers and is thus of relevance to the present study and is further discussed later. A few additional social science studies on farmers' practices, looking at overall biosecurity measures, have been published recently (Higgins et al., 2018; Naylor et al., 2018; Shortall et al., 2018). Overall, however, research in the area is limited, and attention by social scientists to antibiotic use in farming and biosecurity measures is recent and incomplete.

With the lack of social scientists in studies on how to improve farm animal health and welfare in general (Burton et al., 2012) and on how to reduce the development of antibiotic resistance in farming, existing studies in the reductionist tradition of science have focused on individual farmers, failing to connect these with the wider context in which they live and act. For example, Jansen et al. (2009) studied farmers' attitudes toward mastitis treatment but not how these are shaped by the socioeconomic and political context. Lam et al. (2017) present a detailed study on implementation of a model influencing farmers to change behavior with regard to antibiotic use and reported success of the model in influencing farmer behavior. However, like Jansen et al. (2009), they paid limited attention to the role of external drivers and barriers in shaping farmers' behavior. Based on interviews with organic farmers in France, Germany, Spain, and Sweden, Jones et al. (2016) acknowledged that increasing availability of knowledge about appropriate practices will not change farmers' practices and that research is needed on underlying drivers and barriers. Nevertheless, these underlying drivers and barriers are not further studied. In summary, the ways in which farmers' treatment of their animals is socially and culturally shaped and stimulated or hindered by structural societal factors such as market prices, policies, and regulations remain largely uninvestigated although mentioned in the literature as potentially determining farmers' practices with regard to animal health, welfare, and sickness (e.g., Jones et al., 2016). Thus, such studies are needed to better understand the reasons behind certain practices and to deal with antibiotic resistance in agriculture.

\section{THEORY}

As pointed out by Burton (2004), it is clear that farmers' attitudes and behavior to a large extent are socially and culturally shaped. Although this so far has had a limited effect on veterinary and epidemiological research, it has led numerous studies on farmers' environmental management, livestock husbandry, and wider agricultural practices to embrace a wider understanding of behavior as being socially constructed. In particular, the importance of the enculturation of farmers into embodying what it is to be a good farmer has been in focus. Agricultural research has come to embrace a perspective of individual behavior as socially shaped through the theoretical lens of symbolic interactionism (Burton, 2004; Stryker, 2008; Ellis, 2013) or Bourdieu's $(1977,1986)$ theory of social change and continuity (in particular, his concepts of habitus, field and capital; Haggerty et al., 2009; Sutherland and Darnhofer, 2012; Saunders, 2016). Central to symbolic interactionism is that the individual and society are in a coproductive relationship and that the development of self-identity is a social process. With this comes the notion that when we listen to what farmers say and see what they do, we should interpret it as partly a reflection of wider social structures rather than as only individual behavior produced in isolation. Bourdieu's conceptual framework helps acknowledging the 2-way relationship between social and political structures and individual behavior. Structures are both shaped by and act through human bodies and minds. Individual attitudes and behavior should thus not be interpreted as isolated from the structural dimension of society, but in part we can see the work of larger structure in individual action (e.g., the naturalization of productionist agriculture expressed in farmer attitudes). Research in this theoretical tradition has shown how farmers sharing cultural, social, and political economic context come to share an understanding of what it is to be a good farmer.

Several studies point out that high production levels are central for identifying good farmers across contexts in neoliberal society and that the goal of maximizing production is naturalized by farmers (as by members of 
society in general; Burton, 2004; Haggerty et al., 2009; Shortall et al., 2018). An important point to make is that farmers maximize production not only because they want to make good money (which would represent individualized and rational behavior) but also because it represents being a good farmer (i.e., it makes them accepted and valued by their peers; Burton, 2004).

With regard to animal husbandry, there comes a particular tension in this identity of a good farmer. Studies have found across contexts that maximizing production and taking good care of one's livestock are central features associated with being a good farmer (Ellis, 2014; Shortall et al., 2018). This might be particularly so with cattle in general and dairy cows in particular. Ellis (2013) points out that the size of cattle bodies makes it essential that farmers actually interact and work with the animals and that this direct interaction makes it difficult to emotionally separate oneself from them. Thus, taking good care of the animals is not only about being accepted in the eyes of ones' peers but also about an emotional attachment to the animals. Bock et al. (2007) drew attention to how the close daily contact with dairy cows makes the emotions that farmers show for dairy cows stronger than for other farm animals. Several authors also emphasized that the 2 factors of high productivity and giving cows a good life to some extent are in conflict, increasingly so in capitalist agriculture (Wilkie, 2005). Farmers have to manage their emotional bonds to their cattle in ways that still make it possible for them to treat them as commodities.

There are several examples of how farmers might embody the tension between care and production. Shortall et al. (2018) and Swinkels et al. (2015) grouped farmers into 2 "ideal" types of farmers - the large-scale commercial farmer versus the traditional stock keeper-for whom being a good farmer means partly different things. The traditional stock keeper in particular values manual handling of the animals and views being good at judging animal health and welfare by eye as central to being a good farmer. The large-scale commercial farmer associates being a good farmer with being business minded and open to change and making use of modern biosecurity data instead of judging the animal by eye, which is seen as less reliable. The commercial farmer also avoids the kinds of traditional reciprocal interactions and exchanges that characterize being a good neighbor, and thus a good farmer, for the traditional stock keeper. Shortall et al. (2018) showed how the size of the herd matters for how easy it is for a farmer to distance him- or herself form the cattle and see them as commodities, and Wilkie (2005) pointed out that ascribing to a commercial farmer identity makes it easier to maintain a detached relationship to one's cows but that this also is connected to commercial farmers managing bigger herds. Holloway (2007) suggested that the introduction of automatic milking systems (AMS) also facilitated this distancing. Ellis (2014), studying ranchers and beef cattle, drew out 3 dimensions of how farmers manage this tension and their emotions: a sense of responsibility (for producing meat for humans to eat and for taking good care of the cattle), a sense of dominion (i.e., that humans are morally allowed to make use of animals and that this is part of the natural order of things), and the idea that cattle living and dying is part of the cycle of nature (Ellis, 2014).

Although the concept of the good farmer has been important for drawing attention to the social construction of individual behavior, what farmers say and do is not only influenced by what other farmers think but also fundamentally steered by the political and economic context in which they live (Bourdieu, 1986). Agricultural policies, milk prices, and so on are important structures for the ways farmers can practice their farming, and these become embodied in farmers' practices and perspectives (e.g., as a result, it might be very difficult for a farmer to envision a production system that does not aim for maximizing output).

In summary, we can expect farmers' practices and talk about antibiotic use in dairy farming to be a reflection not only of their personal attitudes but also of the wider culture of dairy farming as well as the larger political economy. In addition, the welfare of the animals is expected to be central for the farmers both for personal and emotional reasons and because taking good care of one's cows is an important feature of being a good farmer.

\section{MATERIALS AND METHODS}

Ten farms were selected for the purpose of an exploratory and empirically driven study (in the tradition of grounded theory; Strauss and Corbin, 2012) on how Swedish dairy farmers reason around antibiotic use and resistance in relation to their farm practice and wider situation. These 10 farms were selected from a larger sample of 60 dairy farms (30 organic and 30 conventional) included in a project about antibiotic use and antibiotic resistance on dairy farms. The 60 farms were selected to reflect the variation in conditions for dairy farming in Sweden regarding geographical spread and ecological and socioeconomic circumstances. The exploratory study was expected to yield novel insights into a comparatively unexplored topic. The starting point was that farmers' practices and views on animal husbandry, antibiotic use, and their wider situation reflect not only that farmer as an individual but also 
the wider field within which farmers act (Bourdieu, 1977; Sutherland and Darnhofer, 2012; Saunders, 2016; Naylor et al., 2018).

For the purpose of interviewing a broad variety of Swedish dairy farms, selection was based on the following criteria: (1) equal inclusion of organic and conventional farms (4 conventional and 3 organic farms were included in the final sample) and (2) a variety of production conditions. In addition, we chose to select farms with a comparatively high prevalence of antibiotic-resistant bacteria. The 10 selected farms fell within the upper third quartile of the herds in the larger sample of 60 farms. The median within-herd prevalence of antibiotic-resistant bacteria in the 10 selected herds was $80 \%$ (range: $60-100 \%$ ) in feces samples from 5 calves (unpublished data). As resistance development is complex and affected by many factors, we did not assume that these farms would have different management routines than farms with lower resistance levels. Rather, the purpose of this criterion was the expectation that these farmers would be more likely to have thought about antibiotic resistance and therefore interested in discussing antibiotic use and resistance with us.

The selected farmers were contacted by phone by the second author, who had visited the farms previously within the broader project. The farmers were informed about their comparatively high prevalence of antibiotic resistance and asked if they were willing to participate in a follow-up interview about their thoughts regarding antibiotic use and resistance.

Semistructured interviews were conducted jointly by the second and third authors (the first author was present at one of the interviews) based on an interview guide developed by the third author with input from all other authors. The topic guide helped ensure that we covered themes that we identified as relevant (e.g., reasoning around animal welfare and disease and antibiotic use and resistance) while at the same time giving the informant room to expand on issues that they saw as related to the subject (Bernard, 2006). Starting off with a general description of the farm and its history, the day-to-day routines of the dairy farm, and family relations, the interview then moved on to questions on animal care, animal welfare and health, and the farmers' relations with veterinarians, agribusiness consultants, and representatives of public bodies. Finally, the interviewers sought informants' views on antibiotics, agricultural legislation, and trade. This funneling design aimed to give the informants ample room to describe their situation and put them at ease while at the same time ensuring that we did not miss any information of vital importance for the wider research topic.
We assured our informants that their answers would be anonymized and that our aim was to map their thoughts and practices regarding antibiotics, not to judge them. We stopped interviewing new farms when we reached theoretical saturation in the topics discussed, meaning that no further theoretical development could be done by conducting additional interviews (Strauss and Corbin, 2012). This appeared to occur after interviewing 5 farms and was confirmed in 2 additional interviews. Thus, the final sample was 7 farms (4 conventional and 3 certified organic).

The interviews were performed with the person with key overall responsibility for the farm (i.e., the farm owner or the spouse with the most responsibility for dairy farming). The interviews lasted between 1 and $2 \mathrm{~h}$, and other family members or hired farm workers often joined in. All farms were also visited by one of the authors at least once when the farmer showed us the farm, dairy cows, calves, and barns. By observing the farmers moving around their farm and animals, practices that stem from tacit knowledge that seemed commonsensical to the farmers could be observed (Bernard, 2006). This type of direct observation thus helped us interpret the interviews and made it possible to acknowledge relational practices between farmer, farm workers, and animals.

All interviews were recorded and transcribed. The interview transcripts were coded inductively by the first author to identify emerging themes (Bernard, 2006; Strauss and Corbin, 2012). Detailed notes of observations and immediate reflections in conjunction with interviews and farm observations acted as support in considering and refining emerging themes. To ensure the anonymity of our informants, we have left out geographical information, and all farms are given numbers in the text. When we quote farmers talking about other persons, these are given fictitious names for anonymization.

\section{RESULTS}

\section{Overview of the Farms}

The farms in the study were family farms [which can be defined as "managed and operated by a family and predominantly reliant on family labor" (FAO, 2013); as such, most farms in Sweden and Europe remain organized as family farms (Davidova and Thomson, 2014)] located in a variety of geographical settings (regarding, e.g., the surrounding landscape and proximity to urban centers) and at the time of visit had between 50 and 150 milking cows (see Table 1). At least 1 person in the household worked full time in farming on all farms, and other family members were also engaged in farming on 
a full- or part-time basis. Three of the farms regularly hired farm workers. Two farms were very reliant on 1 full-time family worker (although other family members and seasonal workers were also hired). Although this resulted in particularly hard work and being very much alone with the animals, it was also described as a potential benefit for animal health and welfare:

I think that maybe I see - the fact is that I'm in the barn myself most of the time and I know my animals. If you use a lot of staff it may be easier to miss something, . . . but because I see them every day and handle them, I think I should be able to discover if things aren't right with them. (farm 6 , organic, 62 milking cows)

Five of the farms had been taken over from parents, and the other 2 farms had been purchased by the current owners, but the owners came from dairy farming families. As a result, all the farmers had long-term experience in farming, and most of them in dairy farming. All the farmers expressed pride in their work and a strong connectedness to the farm and the cows:

They [cows] are not machines; they are different individuals. Some people are good at looking after children in day care . . . . And some are excellent at operating machinery. And you kind of have a feeling for different things . . . Y Yes, cows are easier to manage [than children]. But they're kind of the same thing. You can give anyone at all a job in day care but it doesn't work out for everyone. (farm 4, organic, 65 milking cows)

\section{Daily Work and Relationship with the Cows}

Compared with other animal husbandry, dairy farming means having particularly close daily contact with the animals. All farmers interviewed attend to the cows at least twice a day, for milking but also for feeding, cleaning, insemination, heat detection, monitoring calvings, taking care of calves and sick animals, and so on. Although the attention needed by the animals often means that it is difficult for the farmer to take time off, many of the farmers interviewed also pointed out the close daily contact with the animals as a reason for having chosen dairy farming:

Dairy cows are much nicer than beef cows .... The cows are everything to me. (farm 1 , conventional, 75 milking cows)

And this is-I have sat in offices, I have tried being a teacher, I have been in the construction

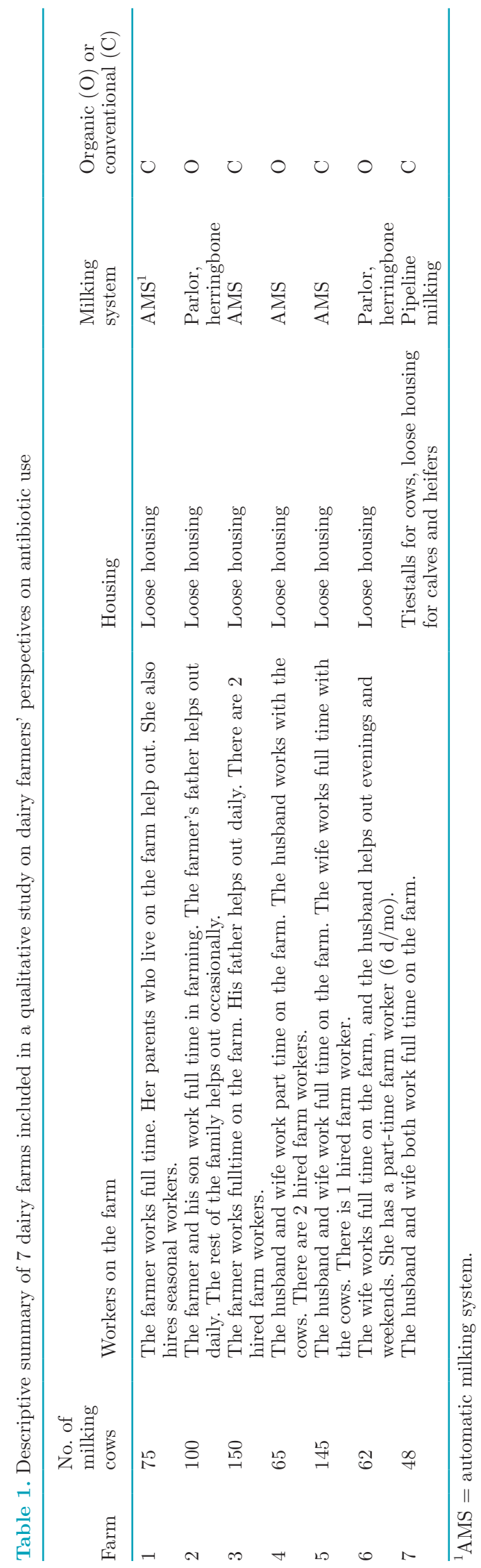


industry, and I'm back to cows and working in farming because this is one of the best jobs, I think, and that's why people keep going. For no one makes any money, you don't do this for the sake of the money. Definitely not. (farm 4, organic, 65 milking cows)

\section{Animal Health and Welfare}

The farmers mentioned several routines they considered important for limiting illness in general: breeding for healthy animals, keeping the barn clean, ensuring sufficient amounts of bedding in the cubicles, identifying and separating sick cows from the others, and milking cows with mastitis after healthy cows to avoid spread of bacteria. All farmers except 1 (who had the philosophy that "a bit of dirt scours out the system") were also very restrictive with visitors and insisted on us wearing protective gear when we entered the barn:

Yes, we try to push sales reps out of the barn-we can't have just anyone going into the barn without protective clothing. (farm 2, organic, 100 milking cows)

However, it was not always easy in practice to keep to the routines acknowledged as optimal from a disease prevention perspective. For example, 2 farmers had been visited by locally settled refugees coming to the farm to buy milk, which led to a conflict between wanting to welcome the refugees and keeping to the routines regarding preventing infection. A couple of farmers also stated that they had experienced disease in their herds as a result of purchasing "bad" (i.e., disease-contaminated) fodder.

An important way to reduce the risk of introducing disease into the herd, adopted by all farmers, was to avoid purchasing new animals. All farmers bred their own replacement heifers and all avoided purchasing new animals, explicitly to prevent disease entering the herd. Although this is recommended practice in Sweden for animal health reasons, it may lead to suboptimization of the farming business as more calves than needed are raised. Thus, this practice can be seen as an example of where disease prevention was prioritized despite compromising financial returns.

Overall, the interviews indicated that animal health and welfare and the productivity of the cows was important for the farmers, and not only in economic terms. Several of the farmers described producing more than $10,000 \mathrm{~kg}$ of $\mathrm{ECM} /$ cow per year in a way that made it clear that this was an important point of appreciation between peers and a symbol of being a good farmer.
High-producing cows were often described as creating a special emotional attachment with the farmer:

These cows that milk 60 liters, they're your favorites, of course. (farm 5, conventional, 145 milking cows)

At the same time, it was clear from the interviews that the farmers' care for the health and welfare of the cows clearly went beyond being a mere economic calculation:

And sick animals - it's really bad to have sick animals. It's costly, but it's also upsetting, it affects you psychologically. (farm 3, conventional, 150 milking cows)

Indeed, all the farmers in different ways expressed strong emotional ties and a sense of responsibility for treating their cows well.

The meat is better if you know the animals and treat them well. That makes for tastier meat. So it's good. (farm 6, organic, 62 milking cows)

I think it's about you liking them. You look at them. You don't just go round scraping manure, you look at the animals and you talk to them and keep an eye on how they're doing. So having an "eye for animals" is more about taking an interest. (farm 4, organic, 65 milking cows)

\section{A Good Farmer Can Judge Animal Health Status by the Eye}

An important aspect of animal health pointed out repeatedly in the interviews was that the farmers and farm workers spend much time with their animals and learn to see if something is wrong:

I have a feeling that all the cows are seen every day here, by me. And I generally recognize them, I look at the ears and eyes and the stance. Since I spend a lot of time in the barn, I see the patterns of movement-this one hasn't moved very much .... So that's probably my way of taking care of them. I have gotten to know these individuals so well that I can notice quite quickly - or very quickly. (farm 1, conventional, 75 milking cows)

You see if something's not right. It's mainly the eyes. It's your own perception. You see directly if she's eating a bit more slowly, or she may be refusing to eat up properly, or she walks a bit 
differently to how she did recently. (farm 7, conventional, 48 milking cows)

Being able to judge the animals by the eye was a biosecurity strategy repeatedly mentioned by the farmers. To some extent the possibility to do so depends on the size of the herd. This was mentioned by many of the farmers, who nevertheless all thought that their own farm was sufficiently small to enable this visual overview. The farmers in this study had between 50 and 150 milking cows, which in an international comparison is relatively small.

\section{AMS}

Four of the 7 farms used AMS for milking. Our interviews indicate that AMS, and the associated computerization, facilitates disease and health management:

Interviewer: Do you have to call out the vet for mastitis, or can you handle it?

Respondent: Well, I don't know when we had to [call the vet for mastitis] last now. No, I don't think we've had to since we got the robot. (farm 1, conventional, 75 milking cows)

In fact, some farmers pointed out that the AMS gave them more time to actually walk around and look at the cows. It provided both detailed and regular data and released time for more thorough visual overview and treatment:

Yes, with the robot you can see it so early when you have the cell counts and the conductivity. You soon see which quarter is affected. And so you leave out that quarter and see that the cell count is now zero. So you know that's it. And then you have to look after that cow and catch it and milk out that quarter. (farm 1, conventional, 75 milking cows)

It has been more or less difficult for the farmers to adjust their animals to being milked by AMS. It is not only about training the animals to accept a new practice but also about genetically adjusting the herd through selective breeding work:

So I think it takes a while to get going fully with the robot, until you have got rid of all those cows that won't work in the robot, quite simply. Some go at once, for they simply don't suit the robot in practice - they have the wrong teats, their udder is too low, and so on. (farm 4, organic, 65 milking cows)

Our findings indicate that farmers may keep very close bonds and daily relationships with their cows even when using AMS. For example, farmer 5, with 145 cows and 2 AMS, spends much time with the cows and has a very emotional and close relationship with them:

I can say that there are probably only 10 animals that I don't recognize out here . . . . So I know nearly all of them, I know their temperament. But it's because I'm there all the time. (farm 5, conventional, 145 milking cows)

Likewise, the farmer and farm worker on farm 4, with 65 milking cows and 1 robot, are both very close to the cows. The herd was very calm when we visited and clearly accustomed to being handled. The closeness and emotional bond to the cows also emerged in the farmer's words:

They're really friendly animals to work with . . . So I think we have-well, I haven't so much experience of other cows, but I think we have a herd that is really sociable and calm. They're really nice cows to work with. The problem with going out and scraping muck is that you can't get at it, they don't move away. You have to push your way through. (farm 4, organic, 65 milking cows)

The responses also indicate that AMS has significantly improved labor conditions on many farms:

Yes, well, how can I explain this? Well, we havebefore we put in the robot, a year ago there, we were dangerously close to closing down. We were seconds away - we even had a land agent in to look at the farm .... And then a year ago, almost exactly, we started using a robot. And that has changed our life, we can say. It's, well, . . . it's maybe the savior of family farming on the milk side. It means you can actually cope with being a dairy farmer even on a family farm. It had changed life enormously .... We have been able to change our working hours completely. As an employer, I think the robot's excellent. (farm 4, organic, 65 milking cows)

\section{Animal Disease and Antibiotic Use}

The most common health condition in Swedish dairy cows, and that causing the most significant produc- 
tivity losses, is mastitis (udder inflammation). Thus, when asked about disease, the farmers most frequently talked about mastitis. The underlying reason for mastitis can differ but is often bacteriological. The severity of inflammation also differs. During the lactation period, the recommendation is that only more severe inflammations are treated with antibiotics, whereas subclinical mastitis may be treated by having the affected quarter(s) dried off. Overall, the farmers appeared knowledgeable about how to prevent and treat common diseases. For example, when the cow was not clearly ill with mastitis, the farmers generally tried other measures than antibiotic treatment (e.g., they milked the cow more frequently or dried off 1 quarter). Whether and how to treat was also an economic question and depended on factors such as stage of lactation and overall productivity.

Yes, of course, these ones that have been healthy and more high-producing, you care a bit more about them. (farm no. 6 organic, 62 milking cows)

Not following recommended procedures was frequently a result of structural limitations such as the labor burden, economic constraints, or social constraints (e.g., the example of farmers wanting to be friendly to refugees). Although knowing that more frequent milking is the best cure for some mastitis infections and a way to reduce the need for antibiotic treatment, the farmers reported that they did not always manage to do this:

Empty the udder - actually you should probably do more than you do. But it depends on what the day is like, what you're doing here and there, and so on. Sometimes you skimp on that. They should be milked out more than they are. (farm 7, conventional, 48 milking cows)

In addition, taking care of sick animals is very labor intensive. Smaller farmers without much extra labor describe how they sometimes have to kill sick animals because they cannot take the extra workload:

Sometimes, then, it's actually the case that-not just because I don't want to see them suffering or that, but sometimes it's in terms of workload too, in my - what should I say? - view. If there is a cow that's [repeatedly] sick . . . . Should I call Lars [the veterinarian] out again? And keep her in a box, it's an awful lot of extra work with mucking out and treatment, and I maybe have calving at that time ... . I just can't cope, quite simply. (farm 7 , conventional, 48 milking cows)
In line with this overall trend, all the farmers in our study reported that they used antibiotics only when recommended by the veterinarian and when there is no good alternative. Antibiotics are most frequently used for clinical acute mastitis or as dry-cow therapy, and then only on cows with subclinical mastitis. Otherwise, the farmers mentioned that they used antibiotics for milk fever, metritis, pneumonia, wounds, foot rot, and bacterial infections following from rotavirus infection.

As described above, the farmers admitted that they perhaps could make more effort to limit antibiotic use for mastitis (e.g., though being more persistent in milking affected cows). Blanket therapy during dry-off was also reported as having occasionally been the practice suggested by the veterinarian. A farmer who is now very restrictive with using Siccalactin (an antibiotic) for dry-cow therapy described how she previously used it routinely as suggested by her veterinarian:

Lisa [the veterinarian] says that it's better to give Siccalactin more often than to get mastitis afterwards when she has calved. So when she [Lisa] was here, we used a lot of Siccalactin. (farm 5, conventional, 145 milking cows)

Two of the farmers admitted having some antibiotics at home (which is not allowed). One of these farmers mentioned that he had this deal with the veterinarian to have quick access to antibiotics for acute cases during the weekend. The other indirectly indicated that small-scale hoarding of antibiotics is sanctioned by the veterinarian:

Now I don't know what you should do, actually, but what we do in practice, he [the veterinarian] says, "Start giving her now, because she has such a high temperature, and we'll talk again when the culture is ready and see if we're on the right path or if we should change the type." So we often start with a culture and we wait for the answer. And sometimes I may have to go and get the medicine from him, and I may have to start directly if it's some -it's like that. (farm 6, organic, 62 milking cows)

During and for some time after cows are treated with antibiotics, the milk cannot be delivered to the dairy for the sake of avoiding production damage (because antibiotic residues kill, e.g., yogurt culture) and avoiding antibiotic residues in marketed milk products. There is no general recommendation about not giving this milk to calves, but recent research indicates the risk of developing antibiotic resistance when calves are fed milk containing antibiotic residues (Duse et al., 2013, 
2015). As noted by one of the farmers, this has also been discussed in the Swedish farm press (Stiftelsen Lantbruksforskning, 2016). Thus, we asked the farmers about their thoughts and practices around this. Several of the farmers were concerned about giving the calves milk with antibiotic residues, and some claimed they never do so. A recent publication by Emanuelson et al. (2018) indicated that around 30\% of Swedish dairy farmers give milk to calves from cows during the course of antibiotic treatment and that $60 \%$ give milk from the withdrawal period. Others acknowledged feeling conflicted because it did not feel good from an animal health perspective, but it also felt very difficult to throw away milk. One of the organic farmers raised the practical problem of preventing calves suckling treated cows, as organic regulations stipulate that the calf should be together with the mother.

\section{Relationship with the Veterinarian}

It is clear that the relationship and communication with their veterinarian was central for the farmers and highly valued by them. Many pointed out that their choice of veterinarian depended primarily on good communication. They wanted to have a trust-based dialog, where the veterinarian trusted their farming competence and eye for their cows and they trusted the medical expertise of the veterinarian. Other important factors mentioned were that the veterinarian had to be competent in dealing with dairy cows and available outside office hours. However, these aspects were not at all as strongly emphasized. Overall, the farmers seemed to trust and respect the veterinarians' recommendations. The farmers were generally content for the veterinarian to prescribe and decide when medication is needed, and none of the farmers expressed any significant interest in taking more responsibility for medicating their animals.

I feel very uncertain in this area, so I always call Lars [the veterinarian] if there's something. (farm 6 , organic, 62 milking cows)

Interviewer: Have you ever felt that, now we would like to have this compound for this cow, because we know that it works?

Respondent: No. No. That's the veterinarian's department. I read my cows and our friend the veterinarian tells me what I should give them. (farm 1, conventional, 75 milking cows)

Although most of the farmers pointed out the importance of having a good relationship with the veterinarian and being able to ask for advice, all farmers also stated that they call the veterinarian only when they are sure that they cannot cure the animal themselves:

Interviewer: When, at what point, do you think "now I have to make the call"?

Respondent: When I feel that we can't handle it any more. So, she's too poorly. The help we can provide, it's not enough and we have to have help. (farm 1, conventional, 75 milking cows)

The choice of calling the veterinarian is strongly influenced by a cost-benefit calculation, as exemplified in the following comment:

Well, it's a matter of finances. You can't get them [the district veterinarian] out for a calf. It's much, much, much cheaper to kill it [the calf]. Unfortunately. (farm 4, organic, 65 milking cows)

\section{Beyond the Farm}

When asked about their thoughts on the wider politics, regulation, and media debates on farming and antibiotic resistance, all the farmers expressed significant frustration. All were generally unhappy about how their production is portrayed in the media and, they felt a lack of appreciation from the wider society of their work. They mentioned double standards among consumers in general with regard to environmental and animal health concerns:

They eat apples in the big cities and travel to Thailand twice a year. Of course you're disappointed! Who's fighting to keep Sweden open and to put fresh Swedish meat on the table? It's us! And all we get is, well, we're going to eat peas! (farm 5, conventional, 145 milking cows)

They also mentioned double standards inherent in the Swedish politics and regulation on agriculture and antibiotic use:

And it's really, really frightening. And we have to have some kind of big brother in Sweden and we have to have really strict regulations. And I have no problem with them. None at all! I think they're really good. I think the animal welfare laws in Sweden are excellent. The medicine bit is excellent in Sweden and we could improve it even more, and I have no problem with that. But then we damn well shouldn't import stuff either! What's the antibiotic resistance percentage of pork from Germany? (farm 4, organic, 65 milking cows) 
And the [municipality] councils here, with school meals and that, then the council sits and tells us how we should treat our animals. And then when we try to agree on a contract, this makes no difference at all. Then they deal with the other hand and take the cheapest the whole time. That's no way to operate. (farm 3, conventional, 150 milking cows)

In Sweden, it has been forbidden since 1986 to use antibiotics for disease prevention or as growth promotors, and antibiotics are allowed only for therapeutic use when needed and under veterinary consultation. Although specific figures for dairy cows are unavailable, looking at overall antibiotic use in animal husbandry, Sweden has the lowest use of antibiotics of all European Union (EU) member countries, with just above $10 \%$ of the average level used in the EU (EMA, 2017). The farmers in our study were well aware that they face stronger limitations on antibiotic use than farmers in other countries. None of the farmers talked about this as a problem for animal health and welfare or for their overall ability to treat sick animals, but they felt that it was yet another dimension of how they were financially disadvantaged in the globalized food market:

I got Ultrapen at Apoteket [the pharmacist] and it was manufactured for the Danish market . . . . The manufacturer had run out, so they sent Danish Ultrapen to Sweden. And then they had to stick on a new label ..., but that meant you could see what it said on the Danish packaging. And what did it say? Two day's quarantine, or maybe it was one day's quarantine? . . . It was like - the Danes go for, like, two days and we have lots of days. Same compound." (farm 4, organic, 65 milking cows)

\section{DISCUSSION}

The farmers interviewed here represent a mix of organic and conventional farms in terms of size (but without any very large farms, which are rare in Sweden), housing type, division of labor (but largely within the family), and milking system. However, all the farms are family farms, with a long tradition in farming, and all farmers expressed strong ties to their animals.

In line with previous studies in other contexts (Wilkie, 2005; Bock et al., 2007; Ellis, 2013, 2014; Shortall et al., 2018), this study shows how taking good care of one's cows and having a productive farm were of key importance to the farmers and can be seen as central for how they conceptualized being a good farmer. Also supporting previous research findings (Wilkie,
2005; Ellis, 2014; Shortall et al., 2018), in some cases the farmers reported that the perceived best care for the animals conflicted with labor demands or farm finances. In these cases, finances were often (but not always) decisive, although this clearly created emotional distress for the farmer. For example, one farmer sometimes slaughtered animals because she could not cope with the increased workload of caring for repeatedly sick cows, and another farmer felt no choice but to kill calves that suddenly became sick on the weekend.

It has been argued that the intensified production that has occurred in dairy farming over the past decades has increased the tension between good care and productivity in farming but that this rarely is acknowledged in research on the topic (Wilkie, 2005). Although we did not specifically inquire about the upscaling and intensification of dairy farming over time in interviews and it was not mentioned by the farmers, it might be an important, but largely overlooked, structural factor determining animal health and welfare and the associated need for antibiotics in dairy farming today. Due to selective breeding, cows are producing vastly larger amounts of milk today than in the past. In Europe, only Denmark has higher productivity per cow than Sweden (Lingheimer et al., 2016). The value placed on having high milk productivity emerged repeatedly in our interviews, but cow longevity was never mentioned. A previous study has found that, when asked, Swedish dairy farmers connected the increased productivity directly with the reduced longevity of modern cows (Bergeå et al., 2016). Reflecting the wider naturalization in the agriculture sector of maximizing production (Haggerty et al., 2009), very few publications on animal health consider this aspect when discussing measures to improve animal health and reduce the need for antibiotic treatment, possibly because of the overall normalization of farm upscaling and intensification that has occurred over time. Three exceptions mention that high productivity has led to increased disease incidence (Derks et al., 2012), including that some farmers and veterinarians are concerned about this (Bergeå et al., 2016; Shortall et al., 2018).

Although dairy cows are held first and foremost for the purpose of producing significant quantities of milk in the capitalist system, as indicated in the pride expressed by some farmers in the interviews regarding their cows' high productivity, our findings show that the emotional attachment that the farmers have to their cows and their sense of responsibility for them is central to their farm management and is an important factor determining agricultural practice. Other studies have similarly found how farmers take significant measures, and might even compromise with farm finances, to meet what they consider being animal health and 
welfare standards that they agree with. A study of dairy farmers in England and Wales found that farmers value animal health and welfare equally to farm profitability (Jones et al., 2015). Similarly, a study on Swedish dairy farmers showed that they are to some extent willing to compromise economic profit to improve animal health and welfare (Hansson and Lagerkvist, 2015). Kolstrup and Hultgren (2011) also showed that dairy farmers with more physical problems have healthier cows, indicating the hard work farmers are willing to put into securing healthy cows.

As described above, our study clearly shows the importance of taking emotions into account when understanding how farmers make decisions in their production. Ellis (2014), studying US ranchers, showed that it takes significant work for farmers to manage their emotions to their cattle in ways that make it possible for them the treat them as commodities. The importance of these emotions and the way they are managed is an explanation for why the ranchers in that study became very upset when "environmentalists" or "people from the city" (who can eat meat without having to kill animals) morally judged their farming as bad for cows or the environment. This is also reported in other studies (Buller et al., 2015; Swinkels et al., 2015). These findings resonate strongly with how our informants expressed significant frustration with how consumers or the general public had concerns about their production without fully understanding what dairy farming is about and the difficulties faced by farmers.

The relationship between being a good farmer, handling emotions in relation to animal production, and having to kill animals is also discussed in a study of mastitis treatment by German and Dutch dairy farmers by Swinkels et al. (2015). They found 2 approaches to cows with clinical mastitis, both motivated by being a good farmer but in different ways. The most common approach was to extend treatment because "farmers who are careful with their cows have older animals" (p. 2375). This was done despite unclear evidence of its clinical utility and despite the increased costs inherent in purchasing antibiotics and wasting more milk. The 2 main reasons for extending treatment identified by Swinkels et al. (2015) were (1) emotional attachment to the cattle and wanting to prevent them from suffering and (2) because taking good care of one's cows is strongly associated with being a good farmer. Less commonly, farmers culled repeatedly sick animals for economic reasons (also associated with being a good farmer). Swinkels et al. (2015) drew on Bock et al. (2007) to connect these 2 strategies (extending treatment or culling) with farmers having attached or detached relationships with their cows, whereby detached farmers are business oriented and may find it easier to kill animals and attached farmers are likely to use more antibiotics. Shortall et al. (2018) similarly found that commercial large-scale farmers associated a good farmer with being business minded, having a more detached relationship with his cows, and focusing more on biosecurity data than judging the animals by the eye. In contrast, the hobby or small-scale farmers in their study expressed stronger emotional attachment to the cows, placed importance on judging animal health status by eye, and emphasized being a good neighbor. We did not observe a similar tendency in the present study, where farmers simultaneously expressed strong emotional attachment to their cows and sometimes saw killing as the best solution for repeatedly ill cows rather than extended medical treatment. All farmers in our study also placed importance on being able to judge animals by eye, and all sought to avoid the kinds of reciprocal relationships with neighbors that would involve a risk of infection (although it was not always easy in practice and sometimes conflicted with the desire to be a good neighbor). It seems reasonable to expect that herd size affects both the farmer's emotional attachment to the cows and the possibility of judging animal health status by eye. However, there were no clear differences in the size of the dairy herds studied by Shortall et al. (2018; 65-365 cows) and Swinkels et al. 2015; average of 88 cows (Germany) and 89 cows (the Netherlands)] and those in our study (48-150 milking cows). On average, a Swedish dairy farm today has 85 milking cows (Bergh, 2018). This indicates that factors other than herd size or degree of commercialization of the farm have a significant effect on farmers' expressed emotional attachment to their cows and their emphasis on the importance for biosecurity of judging animal health status by eye. What united the farms in our study was the farmers' long tradition in farming and the fact that they operated their business as a family farm. It is possible that these aspects have more significant effects on the relationship with the cows than farm size or degree of commercialization (although we did not find any very large farms in any of these studies). This idea resonates with how Ellis (2014) in his study of ranchers in the United States concluded that farmers who were brought up on farms had less difficulty reconciling having attached relationships with their animals with killing them, whereas newer farmers expressed that they struggled with this.

There was also no conflict on the farms we studied between placing importance on knowing individual animals and being able to assess their health status by eye and simultaneously making use of high-tech monitoring equipment and being business oriented. This conflict has been identified in some previous studies (Wilkie, 2005; Shortall et al., 2018). Other studies have 
indicated that large, commercially oriented farming and increased mechanization result in farmers being less emotionally attached to their cows (Wilkie, 2005; Holloway, 2007) and that adoption of AMS has made farmers less competent in judging animal health status by eye (Holloway, 2007). However, the farmers in our sample with AMS had between 65 and 150 milking cows and were seemingly as equally attached to their cows as farmers with fewer cows or without AMS and placed equally significant emphasis on judging animal health status by eye. Similarly, Bock et al. (2007) found that, although unusual in other contexts, some Swedish and French dairy farmers in their study expressed concerned attachment to their cows despite large-scale or business-oriented production.

The farmers we interviewed did not justify antibiotic use by its importance from an animal health and welfare perspective, which has been found in studies in other countries. For example, Swinkels et al. (2015) found that Dutch and German farmers saw society as unfairly viewing them as using too much antibiotics, not understanding that this was essential for animal health and welfare. Buller et al. (2015) studied perspectives on antibiotic use among veterinarians and farmers in the United Kingdom (pig, poultry, and dairy farmers in both indoor and more extensive systems, conventional and organic) and found quite a defensive attitude among farmers, and some veterinarians, who often reported already feeling pressured by stricter antibiotic regulations and unfairly blamed for a large share of the wider societal problem with antibiotic resistance. In the present study, the Swedish farmers rather expressed that antibiotics were used when there was no other alternative or sometimes as a result of lack of time spent on preventive or curative measures (e.g., more repeated milking), which was justified by labor constraints. Moreover, there were no indications in the interviews that the farmers felt that they lacked access to the antibiotics they needed for their animals. Overall, Swedish regulations on antibiotic use in farming have long been stricter than in many other European countries (Lingheimer et al., 2016). Sweden also has stricter animal health and welfare regulations than those required by minimum EU standards and applied in most other EU countries. The Swedish farmers we interviewed seemed to agree with the high animal health and welfare standards and the comparatively strict antibiotic use restrictions and did not express a need for more antibiotics than they had access too. Our findings thus suggest that Swedish farmers' attitudes and behavior of antibiotic use have over time been shaped by the stricter regulations in Sweden, pointing out that structural changes can be important for behavioral change. Rather, the farmers in our study expressed frustration with what they saw as the state's and citizens' double standards in for example, wanting Sweden to keep to comparatively strict animal health and welfare regulations and simultaneously importing food produced under lower standards.

Other studies indicate that the fact that the Swedish farmers in our study, in contrast to farmers in other studies, did not feel limited in their antibiotic use is at least partly a result of them adhering to the comparatively high Swedish animal health and welfare standards (Krieger et al., 2017; Sjöström et al., 2017). This also suggests that the level of antibiotics farmers and veterinarians in other studies perceive they need is in part connected with a culture of using more antibiotics rather than working with animal welfare in other ways. However, Swedish farmers are economically disadvantaged in international trade when competing with farmers who can use more antibiotics and face less strict animal health and welfare regulations. Thus, stricter and more uniform antibiotic legislation in other countries is likely to be effective and would give Swedish farmers international recognition for their efforts to limit antibiotic use.

Although the farmers we interviewed had a clearly negative perception of how consumers and politicians seemingly lacked appreciation for their work, it is clear from our data and from other studies that farmers frequently have significant confidence in the recommendations given by their veterinarian (e.g., Jones et al., 2015; Swinkels et al., 2015). Our data also clearly illustrate that veterinarian practices ultimately determine antibiotic use (and sometimes misuse). Although the trust in authorities in general and in veterinary advice can be expected to vary with the wider political and cultural context, studies in the Netherlands, England, and Wales have also found that farmers place significant trust in their veterinarian (Buller et al., 2015; Jones et al., 2015; Swinkels et al., 2015), which indicates some applicability of this finding beyond Sweden. Only on rare occasions did farmers in our study use antibiotics not prescribed for that purpose, and then often only when sanctioned by their veterinarian. Overall, the farmers trusted their veterinarians, and it appears to be veterinary advice with regard to antibiotic prescription and recommendations, rather than farmers' practices, that determines antibiotic usage in Sweden. This conclusion is supported by, for example, Buller et al. (2015), who point out that we must view veterinarians as critical actors in establishing norms and practices on antibiotic use.

As described in the Introduction, social science engagement in the field remains limited, and much previous research has been shown to take an individualist approach to understanding farmers' behavior, adoption 
of knowledge, and action for change (e.g., Jansen et al., 2009; Jones et al., 2016). For example, drawing on surveys with farmers in England and Wales, Jones et al. (2015) acknowledged a range of political and economic factors causing farmers today to use more antibiotics than would be needed in an ideal situation. Farmers in their study were generally aware of (and concerned about) the risks associated with overuse of antibiotics. Jones et al. (2015) also concluded that stricter legislative measures on antibiotic use would have the most significant effect on reducing usage; however, probably because they do not believe it possible to change this, they went on to focus on changing individual farmers' behavior and introducing policy on increasing information delivery to farmers (despite acknowledging that lack of information is not the key problem). Thus, although the effects of structural factors, such as the wider political climate, market structures, and regulations, are increasingly being recognized, this has yet to influence the wider body of research on farmers' behavior, which remains rather individualistic. We have shown here how the concept of the good farmer and attention to the emotional dimensions of farming can be helpful lenses through which we can better understand the factors beyond economy and knowledge of importance for determining farmers' decisions in production in general and regarding antibiotic use. The findings in the present study, together with emerging social science engagement on the topic, also call for increased attention to wider societal reasons for why farmers behave as they do and for inclusion of the wider societal area (i.e., moving beyond the behavior of farmers) when targeting antibiotic resistance.

\section{CONCLUSIONS}

With this study, we aimed to fill a research gap regarding social science studies on antibiotic usage in farming. In particular, we sought to provide qualitative data on how and why antibiotics are used and situated in the wider farm practice, which is essential information in identifying relevant actions for change. Overall, we found that Swedish dairy farmers place high value on animal health and welfare for economic and emotional reasons and that they balance economic and labor costs against efforts in improving animal health and welfare. We also found that they are knowledgeable about what creates disease and how to prevent it but place strong trust in their veterinarians and are not interested in taking more responsibility for prescribing medication than they already have. When they fail to do all they can to ensure animal health and welfare, this is often due to economic factors or labor constraints rather than lack of knowledge or lack of access to medication. We concluded the following:

1. Swedish farmers do not feel that the stricter antibiotic regulations in Sweden hamper their animal health and welfare work, although they do believe it places them at a financial disadvantage on international markets. This indicates that reluctance among farmers and veterinarians elsewhere in the world to reduce use of antibiotics for animal health and welfare motives might be partly unjustified.

2. The veterinarian is an important authority for Swedish farmers, and veterinary advice largely determines antibiotic use.

3. Overall structural factors (e.g., labor, financial concerns, and the overall structure of modern dairy farming) are key in determining animal health and welfare work, as are farmers' emotions and sense of responsibility for their animals. These factors are addressed only to a limited extent in veterinary research today and deserve more attention in future research on the topic.

\section{ACKNOWLEDGMENTS}

We thank the farmers interviewed in this study for taking time to talk with us and openly share information about their farming, their perspectives on antibiotic use and resistance, and their daily farm challenges. Funding was provided by Formas - The Swedish Research Council for Environment, Agricultural Sciences and Spatial Planning (grant 2014-281; Stockholm, Sweden).

\section{REFERENCES}

Bergeå, H., A. Roth, U. Emanuelson, and S. Agenäs. 2016. Farmer awareness of cow longevity and implications for decision-making at farm level. Acta Agric. Scand. A Anim. Sci. 66:25-34. https:// doi.org/10.1080/09064702.2016.1196726.

Bergh, A. 2018. Marknadsrapport Mjölk och Mejeriprodukter. Swedish Board of Agriculture, Jönköping. Sweden.

Bernard, R. H. 2006. Research Methods in Anthropology: Qualitative and Quantitative Approaches. 4th ed. AltaMira Press, Oxford, UK.

Bock, B., M. van Huik, M. Prutzer, F. Kling Eveillard, and A. Dockes. 2007. Farmers' relationship with different animals: The importance of getting close to the animals. Case studies of French, Swedish and Dutch cattle, pig and poultry farmers. Int. J. Sociol. Agric. Food 15:108-125.

Bourdieu, P. 1977. Outline of a Theory of Practice. Cambridge University Press, Cambridge, UK.

Bourdieu, P. 1986. The forms of capital. In Handbook of Theory of Research for the Sociology of Education. J. G. Richardson, ed. Greenwood Press, New York, NY.

Buller, H., S. Hinchcliffe, J. Hockenhull, D. Barrett, K. Reyher, A Butterworth, and C. Heath. 2015. Systematic review and social research to further understanding of current practice in the context of using antimicrobials in livestock farming and to inform 
appropriate interventions to reduce antimicrobial resistance within the livestock sector. Department for Environment, Food and Rural Affairs, London, UK.

Burton, R. J. F. 2004. Seeing through the "good farmer's" eyes: Towards developing an understanding of the social symbolic value of "productivist" behaviour. Sociol. Ruralis 44:195-215. https://doi org/10.1111/j.1467-9523.2004.00270.x

Burton, R. J. F., S. Peoples, and M. H. Cooper. 2012. Building "cowshed cultures": A cultural perspective on the promotion of stockmanship and animal welfare on dairy farms. J. Rural Stud. 28:174187. https://doi.org/10.1016/j.jrurstud.2011.12.003.

Davidova, S., and K. Thomson. 2014. Family Farming in Europe: Challenges and Prospects. European Union, Brussels, Belgium.

Derks, M., L. M. van de Ven, T. van Werven, W. D. Kremer, and H. Hogeveen. 2012. The perception of veterinary herd health management by Dutch dairy farmers and its current status in the Netherlands: A survey. Prev. Vet. Med. 104:207-215. https://doi.org/10 .1016/j.prevetmed.2011.12.019.

Duse, A., K. P. Waller, U. Emanuelson, H. E. Unnerstad, Y. Persson, and B. Bengtsson. 2013. Farming practices in Sweden related to feeding milk and colostrum from cows treated with antimicrobials to dairy calves. Acta Vet. Scand. 55:49.

Duse, A., K. P. Waller, U. Emanuelson, H. E. Unnerstad, Y. Persson, and B. Bengtsson. 2015. Risk factors for antimicrobial resistance in fecal Escherichia coli from preweaned dairy calves. J. Dairy Sci. 98:500-516.

Ellis, C. 2013. The symbiotic ideology: Stewardship, husbandry, and dominion in beef production. Rural Sociol. 78:429-449. https://doi .org/10.1111/ruso.12031.

Ellis, C. 2014. Boundary labor and the production of emotionless commodities: The case of beef production. Sociol. Q. 55:92-118. https: //doi.org/10.1111/tsq.12047.

EMA (European Medicines Agency). 2017. Sales of veterinary antimicrobial agents in 29 European countries in 2015. Trends from 2010 to 2015. 7th European Surveillance of Veterinary Antimicrobial Consumption report. EMA, London, UK.

Emanuelson, U., K. Sjöström, and N. Fall. 2018. Biosecurity and animal disease management in organic and conventional Swedish dairy herds: A questionnaire study. Acta Vet. Scand. 60:23.

FAO (Food and Agriculture organization of the United Nations). 2013. International Year of Family Farming 2014 Master Plan. Accessed Dec. 17, 2018. http://www.fao.org/fileadmin/user_upload/iyff/ docs/Final_Master_Plan_IYFF_2014_30-05.pdf.

FAO (Food and Agriculture Organization of the United Nations). 2016. The FAO Action Plan on Antimicrobial Resistance 20162020. Accessed Oct. 31, 2018. http://www.fao.org/3/a-i5996e.pdf.

Haggerty, J., H. Campbell, and C. Morris. 2009. Keeping the stress off the sheep? Agricultural intensification, neoliberalism, and "good" farming in New Zealand. Geoforum 40:767-777. https://doi.org/10 .1016/j.geoforum.2008.12.003.

Hamilton, L. 2017. Bridging the divide between theory and practice: Taking a co-productive approach to vet-farmer relationships. Food Ethics 1:221-233. https://doi.org/10.1007/s41055-017-0011-7.

Hansson, H., and C. J. Lagerkvist. 2015. Identifying use and non-use values of animal welfare: Evidence from Swedish dairy agriculture. Food Policy 50:35-42.

Higgins, V., M. Bryant, M. Hernández-Jover, L. Rast, and C. McShane. 2018. Devolved responsibility and on-farm biosecurity: Practices of biosecure farming care in livestock production. Sociol. Ruralis 58:20-39. https://doi.org/10.1111/soru.12155.

Holloway, L. 2007. Subjecting cows to robots: Farming technologies and the making of animal subjects. Environ. Plan. D Soc. Space 25:1041-1060. https://doi.org/10.1068/d77j.

Jan, J., W. M. A. McIntosh, H. M. Scott, and W. Dean. 2010. The effects of moral obligations to others and others' influence on veterinarians' attitudes toward and recommendations to utilize antibiotics in feedlot cattle. J. Rural Soc. Sci. 25:122-148.

Jansen, J., B. H. P. van den Borne, R. J. Renes, G. van Schaik, T. J. G. M. Lam, and C. Leeuwis. 2009. Explaining mastitis incidence in Dutch dairy farming: The influence of farmers' attitudes and behaviour. Prev. Vet. Med. 92:210-223. https://doi.org/10.1016/j .prevetmed.2009.08.015.

Jones, P. J., E. A. Marier, R. B. Tranter, G. Wu, E. Watson, and C. J. Teale. 2015. Factors affecting dairy farmers' attitudes towards antimicrobial medicine usage in cattle in England and Wales. Prev. Vet. Med. 121:30-40. https://doi.org/10.1016/j.prevetmed.2015.05 .010 .

Jones, P. J., J. Sok, R. B. Tranter, I. Blanco-Penedo, N. Fall, C. Fourichon, H. Hogeveen, M. Krieger, and A. Sundrum. 2016. Assessing, and understanding, European organic dairy farmers' intentions to improve herd health. Prev. Vet. Med. 133:84-96. https:// doi.org/10.1016/j.prevetmed.2016.08.005.

Kolstrup, C. L., and J. Hultgren. 2011. Perceived physical and psychosocial exposure and health symptoms of dairy farm staff and possible associations with dairy cow health. J. Agric. Saf. Health 17:111-125.

Krieger, M., K. Sjöström, I. Blanco-Penedo, A. Madouasse, J. E. Duval, N. Bareille, C. Fourichon, A. Sundrum, and U. Emanuelson. 2017. Prevalence of production disease related indicators in organic dairy herds in four European countries. Livest. Sci. 198:104-108. https://doi.org/10.1016/j.livsci.2017.02.015

Lam, T. J. G. M., J. Jansen, and R. J. Wessels. 2017. The RESET Mindset Model applied on decreasing antibiotic usage in dairy cattle in the Netherlands. Ir. Vet. J. 70. https://doi.org/10.1186/ s13620-017-0085-x.

Lingheimer, I., K. Johansson, E. Jirskog, Å. Lannhard Öberg, and M. Törnquist. 2016. Marknadsöversikt- mjölk och mejeriprodukter (Market overview milk and dairy products). Rapport 2016:11.

McIntosh, W. M. A., S. Schulz, W. Dean, M. H. Scott, K. S. Barling, and I. Takei. 2009. Feedlot veterinarians' moral and instrumental beliefs regarding antimicrobial use in feedlot cattle. J. Community Appl. Soc. Psychol. 19:51-67. https://doi.org/10.1002/casp.976.

Naylor, R., A. Hamilton-Webb, R. Little, and D. Maye. 2018. The "good farmer": Farmer identities and the control of exotic livestock disease in England. Sociol. Ruralis 58:3-19. https://doi.org/ $10.1111 /$ soru. 12127 .

Saunders, F. P. 2016. Complex shades of green: Gradually changing notions of the "good farmer" in a Swedish context. Sociol. Ruralis 56:391-407. https://doi.org/10.1111/soru.12115.

Shortall, O., L. A. Sutherland, A. Ruston, and J. Kaler. 2018. True cowmen and commercial farmers: Exploring vets' and dairy farmers' contrasting views of "good farming" in relation to biosecurity. Sociol. Ruralis 58:583-603. https://doi.org/10.1111/soru.12205.

Sjöström, K., N. Fall, I. Blanco-Penedo, J. E. Duval, M. Krieger, and U. Emanuelson. 2017. Lameness prevalence and risk factors in organic dairy herds in four European countries. Livest. Sci. 208:4450. https://doi.org/10.1016/j.livsci.2017.12.009.

Stiftelsen Lantbruksforskning. 2016. Karensmjölk till kalven ökar risken för antibiotikaresistens. Vol. 2018. Stiftelsen Lantbruksforskning, Stockholm, Sweden.

Strauss, A. L., and J. M. Corbin. 2012. Basics of Qualitative Research: Techniques and Procedures for Developing Grounded Theory SAGE, Thousand Oaks, CA.

Stryker, S. 2008. From mead to a structural symbolic interactionism and beyond. Annu. Rev. Sociol. 34:15-31. https://doi.org/10 .1146 /annurev.soc.34.040507.134649.

Sutherland, L. A., and I. Darnhofer. 2012. Of organic farmers and "good farmers": Changing habitus in rural England. J. Rural Stud. 28:232-240. https://doi.org/10.1016/j.jrurstud.2012.03.003.

Swinkels, J. M., A. Hilkens, V. Zoche-Golob, V. Krömker, M. Buddiger, J. Jansen, and T. J. G. M. Lam. 2015. Social influences on the duration of antibiotic treatment of clinical mastitis in dairy cows. J. Dairy Sci. 98:2369-2380.

WHO (World Health Organization). 2017. Fact Sheet: Antimicrobial Resistance 1-5. WHO, Geneva, Switzerland.

Wilkie, R. 2005. Sentient commodities and productive paradoxes: The ambiguous nature of human-livestock relations in Northeast Scotland. J. Rural Stud. 21:213-230. https://doi.org/10.1016/j .jrurstud.2004.10.002. 